\title{
Social Psychology of Mental Health: The Social Structure and Personality Perspective
}

\author{
Esteban Sánchez Moreno and Ana Barrón López de Roda \\ Complutense University of Madrid
}

\begin{abstract}
Previous research has revealed a persistent association between social structure and mental health. However, most researchers have focused only on the psychological and psychosocial aspects of that relationship. The present paper indicates the need to include the social and structural bases of distress in our theoretical models. Starting from a general social and psychological model, our research considered the role of several social, environmental, and structural variables (social position, social stressors, and social integration), psychological factors (self-esteem), and psychosocial variables (perceived social support). The theoretical model was tested working with a group of Spanish participants $(N=401)$ that covered a range of social positions. The results obtained using structural equation modeling support our model, showing the relevant role played by psychosocial, psychological and social, and structural factors. Implications for theory and intervention are discussed.

Keywords: mental health, social structure, social support, self-esteem, social integration
\end{abstract}

\begin{abstract}
La investigación previa ha puesto de manifiesto la existencia de una asociación entre estructura social y salud mental. Sin embargo, la mayoría de los investigadores se ha centrado en los aspectos psicológicos y psicosociales de dicha relación. El presente trabajo defiende la necesidad de incluir en nuestros modelos teóricos las bases sociales y estructurales del deterioro psicológico. Partiendo de un modelo general, nuestra investigación consideró el papel jugado por diversas variables sociales, ambientales y estructurales (posición social, estresores sociales e integración social), psicológicas (autoestima) y psicosociales (apoyo social percibido). El modelo teórico se puso a prueba utilizando una muestra española $(N=401)$ que incluía diversas posiciones sociales. Los resultados obtenidos, utilizando el análisis de ecuaciones estructurales, apoyaron nuestro modelo, mostrando el relevante papel jugado por los factores psicológicos, psicosociales y estructurales. A la luz de estos datos, se discuten tanto las implicaciones teóricas como las correspondientes a la intervención.
\end{abstract}

Palabras clave: salud mental, estructura social, autoestima, apoyo social, integración social

Correspondence concerning this article should be addressed to either Esteban Sánchez Moreno, Departamento de Sociología, Facultad de CC Políticas y Sociología, Campus de Somosaguas, 28223 Pozuelo, Madrid (Spain). E-mail: esteban.sanchez@ cps.ucm.es; or to Ana Barrón López de Roda, Departamento de Psicología Social, Facultad de Psicología, Campus de Somosaguas, 28223 Pozuelo, Madrid (Spain). E-mail: ana.barron@psi.ucm.es 
Does social structure affect psychological well-being? Do psychological factors have an impact on mental health? These two topics have been traditional areas of interest for sociologists and psychologists, respectively. Nonetheless, few studies exist in which an attempt is made to integrate the combined influence of the two variables. In fact, within social psychology, the two perspectives have seldom been combined. Psychological social psychology has focused its interest principally on variables of a psychological nature, whereas sociological social psychology has focused on the distribution of mental health and illness among the population, following socio-demographic criteria. In our study, we defend a model of mental health that takes into account both psychological and socio-structural influences on individuals' well-being.

House (1977), in his relevant article, added a third face to the classic distinction between the two schools of social psychology: that of psychological sociology, or the study of social structure and personality. This variant of social psychology relates macro-social phenomena to individual behavior patterns and individual psychological attributes. It shares with symbolic interactionism an interest in the real world, but places more emphasis both on macro-social structural concepts and on quantitative empirical methods. At the same time, it shares with psychological social psychology an emphasis on quantitative methods, but focuses more on real, macro-social phenomena, using, where necessary, nonexperimental methods.

According to House $(1977,1981)$, this is the social psychology that can be found in Weber and his research on Protestant ethics and the spirit of capitalism, showing how values and beliefs play an autonomous role in society and can cause important changes in social structure. For further examples, readers are referred to Durkheim (1897), and his classic study linking anomie and suicide; and to Marx (1844), and his concept of alienation. All of the above relate social phenomena to mental states; all of them can be considered examples of the position of social structure and personality within sociology.

More recently, House and Mortimer (1990) insisted on the relative advantages of this perspective in comparison with the other two (Symbolic Interactionism and Psychological Social Psychology). The perspective is characterized by these two aspects: (a) being theoretically focused on the relationship of macro-social phenomena to individual behavior patterns and individual psychological attributes; (b) the use of nonexperimental quantitative methods, where the nature of the problems under investigation should take precedence over the method: the method should be chosen to 'fit' the problem, consistent with what Wicker (1989) called substantive theorizing.

Sociological social psychology, therefore, aims to specify those aspects of social stratification that have the greatest effect on individuals' behavior patterns, how these aspects affect the individual proximally, and under which conditions, and by means of which processes, the effects of social stratification are more or less pronounced.

Among the principal components of social stratification are socio-economic status, sex, race, age, occupational position, etc. The relationship between these components and individual behavior patterns has been clearly documented in numerous studies, as shown, for example, in the extensive literature covering the relationship between social class and health behaviors. However, as House and Mortimer (1990) stated, it is necessary to understand the conditions or proximal stimuli by means of which structural positions affect individuals.

Thus, Williams (1990) showed how certain components of social class can affect health, acting as proximal stimuli. According to this author, social class can affect susceptibility to illness in various ways. This is due to the importance of social class in determining the position occupied by individuals in various institutional sectors, in providing varying access to resources, in influencing individuals' attitudes, ways of thinking, and lifestyle, the amount of stress they encounter, the social bonds they develop, etc.

At the same time, at a lower level of analysis, we should take into account microsocial and psychological processes that contribute to explaining the relationship between social structure and individual behavior. The contributions of social cognition are of key importance here, as schemata, representations, stereotypes, etc., can play a central role in the process by which social stratification systems are maintained and/or modified. And not only are we interested in the way social structure affects individuals, but also the contrary, in other words, the potential influence of individuals on social order. Of especial relevance here are the contributions of those areas of social psychology concerned with how social order and structure emerge from interaction.

This theoretical framework is considered to form the basis of an appropriate socio-psychological approach to the study of mental health. In fact, various studies, ranging from the classic work by Brown and Harris (1978) in Camberwell, or those by Mirowsky and Ross (1989), to more recent research such as that of Turner and Lloyd (1999), can be included in this perspective.

Our study also follows this line of research, that is, focusing on the relationship between social structure and health. In this case, the task is twofold. Firstly, we shall specify, at a macrosocial level, the relevant indexes of health and well-being. Subsequently, we shall study the proximal and psychological mechanisms through which the abovementioned components exert their influence on individual behavior patterns and attributes (Barrón, 1993). According to House (1981), there are three basic principles: (a) the component principle. As the processes of social structure contain multiple aspects or components, we need to clarify which of these components are relevant to our study. In the present study we chose social position. (b) The proximity principle. The effects of social structures are transmitted to 
individuals via stimuli that are in contact with them. Thus, the effect of complex structures on individuals should be understood, generally, in terms of the smaller structures that constitute the proximal social experiences and proximal stimuli in their lives. In our case, we hypothesized that social integration and stress are proximal stimuli. (c) The psychological principle. Our concern here is with the psychological processes that allow interactions and stimuli to be incorporated. In other words, psychological constructs must be used in order to understand and explain the impact of social structures on the individual. In the present case, we propose perceived social support and self-esteem.

Thus, the proposed model is summarized in Figure 1.

With regard to the component principle, the inclusion of social position is essential. The different theories about social stratification, whether Marxist (Poulantzas 1976; Wright, 1994) or Weberian (Giddens, 1973; Parkin, 1979), have granted a privileged position to social class in their analysis of contemporary societies. In any case, reference has generally been made to income level or to social status in order to define membership of any social class. However, recent analyses make clear the need to include the position occupied by individuals as a result of the division of labor in modern societies. According to authors such as Van Parijs (1993), class division should no longer be based on ownership of the means of production or on differential market position, but instead on the uneven distribution of a particular resource: employment. In this respect, the inclusion within our notion of social position of both income level and various employment statuses (employed, unemployed, retired, etc.) was considered relevant.

With respect to the proximity principle, two factors are proposed: stress and social integration. Regarding the first of these, according to Pearlin (1989), stressful experiences do not occur in a vacuum, but are related to social structure and stratification systems such as social and economic class, race, sex, or age. These systems produce an uneven distribution of resources and opportunities, and therefore, low status in any of them could itself be the origin of stressful life conditions (Turner \& Lloyd, 1999). Most researchers in the area of stress begin their work focusing on the potential stressors of individual experiences, while ignoring the possible structural origin of these stressors. From our point of view, however, any psychosociological model should contemplate the sociostructural origin of the stressors, as we consider stressors to be one of the mediators through which social structure is related to mental health.

With regard to social integration, its inclusion in the different theoretical models has been considered from a restrictive, purely psychological perspective, due to the

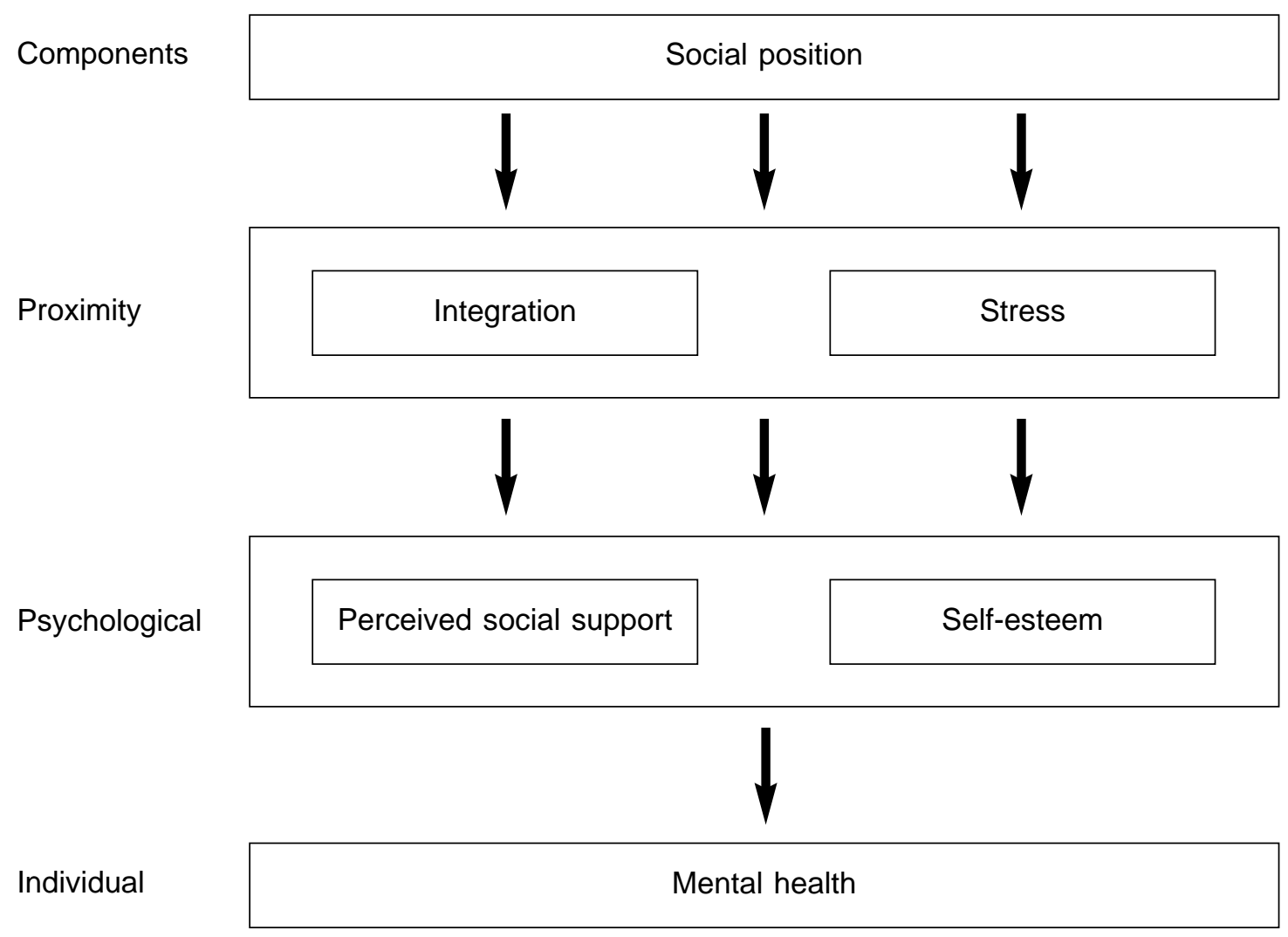

Figure 1. Social structure and mental health. 
confusion of the concept of social integration with that of formal social support. To overcome this deficit, we propose the differentiation between two dimensions of the concept of social integration: integration within the community and alienation. With respect to integration within the community, studies such as those of Kunovich and Hodson (1999) and Lin, Ye, and Ensel (1999) have considered the role of ties that individuals maintain with their community as an indicator of social integration. Being a member of political, economic, cultural, or religious organizations, and the existence of close personal relationships, have been considered indicators of social integration.

Although we consider that all of these aspects constitute dimensions of integration within the community, this is only one aspect of social integration. The work of Durkheim offers a detailed analysis in this respect. The state of anomie can be understood as a dimension of integration, leading to individuals' detachment from their normative environment. In his sociology of suicide, Durkheim (1897) showed how individuals' relationship with their socio-normative environment has behavioral consequences, in this case, suicidal behavior. Durkheim thus treated integration within the symbolic, normative world as an explanatory variable for individual phenomena. In addition, concepts such as alienation (Marx, 1844) refer to the consequences of the relationship between individuals and society (existence of an uncontrollable and senseless world, self-estrangement and cultural estrangement; Seeman, 1959). Therefore, we propose the following definition of social integration: the normative, symbolic, and material states in which individuals find themselves immersed, and which link them to a collective project and regulate their behavior, thus making the everyday world understandable, predictable, and controllable (Sánchez, 1998). In summary, we shall consider social integration as a phenomenon with two dimensions: on the one hand, integration within the community and, on the other, alienation.

Lastly, with regard to the psychological principle, we propose two variables: perceived social support and selfesteem. In studies concerning social influences on mental health, social support has been one of the most widely studied factors. Its influence on psychological well-being has been clearly established (Cutrona, 1986; Gore \& Aseltine 1995; Lin, Ye, \& Ensel 1999; Thoits, 1982; Wethington \& Kessler, 1986), both directly, in the form of an effect that is independent of stress, and as a buffering effect. In the literature on this subject, perceived social support has shown effects that protect the individual from stress (Cohen \& Wills, 1985). Therefore, social integration and stressors can be assumed to influence the perception of support, thus affecting psychological well-being.

Self-esteem also seems to have a beneficial effect on mental health. In this respect, Cochrane and Sobol (1980) showed how individuals with high self-esteem ran a lower risk of psychological deterioration, whereas Roberts and Gotlib (1997) showed the importance of self-esteem in the explanation of the appearance of mental illness and other deviant behavior patterns. Self-esteem is a fundamental factor in accounting for the relationship between social position and mental health. The social origin of the experiences that form the building blocks of self-concept, together with its character as a psychological process, convert self-esteem into an especially important link between socio-economic conditions and mental health. In this respect, various studies (Brage \& Meredith, 1994; Mortimer \& Lorence, 1979) have shown how variations in occupational and domestic/family experiences correspond with variations in self-esteem and sense of personal efficacy and competence.

To summarize, the main hypothesis of our study is that social position is related to mental health at two levels of intervention, proximal and psychological. Specifically, we expect to find the following relationships between the proposed variables:

1. Social position will be inversely related to stress and alienation, and directly related to integration in the community.

2. Stress will be inversely related to self-esteem and to well-being.

3. Alienation will be inversely related to social support and self-esteem.

4. Integration in the community will be directly related to social support and self-esteem.

5. Perceived social support will have a buffering effect.

6. Self-esteem and perceived social support will be directly related to psychological well-being.

\section{Method}

\section{Participants}

In order to reproduce the various socioeconomic groups within the group of participants, we used a cross-sectional design with nonrandom sampling. Thus, the final group was made up of 401 participants, all Spanish residents, with the following main sociodemographic traits: with respect to sex, $44 \%(n=176)$ were women and $56 \%$ were men $(n=225)$. In terms of employment status, $53.1 \%(n=213)$ were working at the time of the interview, $12.7 \%(n=51)$ were unemployed, $13.7 \%(n=55)$ were students, $7.7 \%(n=30)$ were homemakers, and $12.5 \%(n=52)$ were retired. With regard to educational level, $22.7 \%(n=92)$ had not gone beyond compulsory schooling, 38.2\% ( $n=153)$ had either studied the Spanish equivalent of high school (bachillerato) or taken vocational training (formación profesional), and $38.9 \%(n=156)$ had completed university studies. Regarding distribution according to income, $34.4 \%(n=137)$ earned less than $469 €$ per month, $33.2 \%(n=132)$ earned between $469 €$ and $938 €, 21.4 \%(n=88)$ between $939 €$ and 1719 $€$, and $11 \%(n=45)$ earned over $1719 €$. All participants were over 18 years of age, the maximum age being 75 . 


\section{Procedure}

A self-administered questionnaire was used for most of the participants, though it was administered by a researcher to certain groups, such as those over 60 years of age, or those with a very low level of education. Average time for completion of the questionnaire was 45 minutes. All participants were informed of the confidentiality of the data collected, as well as of the main goals of the study.

\section{Measures}

Before the present study, a pilot study had been carried out with 50 sociology students. The basic objectives of this pilot study were to assess the time needed for completion of the questionnaire and the relevance of translating certain scales from the original English. As a result, the questionnaire was reduced in length and some items were eliminated (those relating specifically to the cultural environments for which they were designed - principally Great Britain and the USA). The resulting questionnaire was divided into two blocks. The first block included socio-demographic data: sex, age, marital status, number of household members, employment status, level of education, monthly income, and religious ideology and practice. The second block was divided, in turn, into two broad sections. In the first part, information was gathered about participants' stressful life experiences and their mental health. Included in the second part of the questionnaire were measures of alienation, integration within the community, perceived social support, and self-esteem. The measuring instruments used are described below.

Social position. This is a researcher-developed scale that measures social position by combining the two indexes (level of income and employment status). It is made up of nine categories that range from unemployed with monthly income of less than 468 euros to employed with more than 1718 euros of monthly income. This scale also has categories for retired people, students, and homemakers. Education was not included because its effects depend on income. The categories of the scale are as follows: unemployed with income under $469 €$, unemployed with income between 469 and $938 €$, homemakers and retired people with income under $469 €$, homemakers and retired people with income between 469 and $938 €$, employed with income under $469 €$, employed with income between 469 and $938 €$, unemployed with income up to $1719 €$, employed with income between 939 and $1719 €$, and employed with income over $1719 €$.

Psychological well-being. The General Health Questionnaire (GHQ; Goldberg, 1978) was used to evaluate psychological well-being. This is a self-administered questionnaire, originally designed to detect minor, nonpsychotic psychological disturbances. Its items describe behavior patterns and emotions commonly found in the nonclinical population. It is comprised of 12 items (e.g., Have you been able to concentrate well on what you were doing? Have you ever thought that you were a worthless person?), in which respondents are asked for information about the extent to which they had experienced certain symptoms in the previous weeks. The scoring method used in the present research was the Likert scale, with a range of 0 to 3. High scores indicate low levels of psychological well-being. Its validity has been repeatedly shown both by its association with other measures of psychological wellbeing (Banks, 1983) and by the high level of internal consistency reported in various studies (Hepworth, 1980; Stafford, 1982; Álvaro, 1992). Within the group of participants for the present study, we obtained an internal consistency coefficient of .91 (Cronbach's $\alpha$ ). Factor analysis (principal components method, varimax rotation) revealed two factors (positive interaction and negative affect) that accounted for $61.9 \%$ of the variance.

Stressful life events. The Questionnaire of Stressful Life Events developed by Herrero, Gracia, and Musitu (1996) was used. The logic of its design is similar to that of many other scales of life events, in which respondents report certain events experienced during the past year (e.g., death of spouse, separation, serious problems at work, or financial difficulties) and evaluate the desirability of each event. It consists of 32 items, and offers the possibility of describing other events not included in the questionnaire, but which have been experienced and are considered relevant by respondents. In addition to this, the questionnaire allows participants to indicate events that they consider positive. The total score is thus divided into two parts: on the one hand, the sum of all the negative incidents, and on the other, the sum of the positive incidents.

Social Integration. Two instruments were used to measure this concept.

Alienation. The Alienation Questionnaire by Kohn and Schooler (Kohn, 1976) was used. This questionnaire is made up of 16 items, and is derived from Seeman's (1983) work on the concept of alienation. We chose a Likert-type response format, ranging from 1 (low alienation) to 7 (high alienation). Some examples of the items are as follows: How frequently do you feel bored with everything? There's nothing wrong with coming close to breaking the law as long as you don't get into trouble. How often do your ideas and opinions differ from those of your friends? We obtained an internal consistency coefficient of .85 (Cronbach's $\alpha$ ). In addition, the results of factorial analysis revealed four factors that clearly coincide with the theoretical fundamentals of this scale: self-estrangement, cultural estrangement, anomie, and helplessness. Combined, the four factors account for $62.9 \%$ of the total variance. These analyses coincide with those carried out by Roberts (1987), and confirm the reliability and validity of the questionnaire.

Community integration. For the evaluation of community integration within informal systems, an adaptation of a questionnaire by Herrero, Gracia, and Musitu (1996) was used (Community Integration Questionnaire, Cuestionario de Integración Comunitaria). Given that the original questionnaire 
was considered too long for our purposes, we shortened it according to the statistical criteria from the pilot study. Participants are asked to evaluate the degree of support received from certain informal institutions (sports and cultural associations, social clubs, parish church, etc.) on a scale of 1 to 5 (high scores in the questionnaire indicate high community integration). Although our adaptation was made up of a selection of items from the original questionnaire, the internal consistency coefficient for the present group of participants was very similar to that obtained by Herrero, Gracia, and Musitu (1996): $\alpha=.883$ and $\alpha=885$, respectively. This questionnaire is similar to that used by Lin, Ye, and Ensel (1999) to measure participation in community organizations, such as religious, political, and neighborhood groups.

Perceived social support. An adaptation of the questionnaire by Herrero, Gracia, and Musitu (1996) (Perceived Social Support Questionnaire, Cuestionario de Apoyo Social Percibido) was used to evaluate perceived social support. The adaptation was made on the basis of the same criteria as in the case of the Community Integration Questionnaire. The final questionnaire is composed of seven items in which participants are asked to evaluate to what extent someone personally important to them would be a source of various types of support: instrumental, emotional, and informational. The scoring for each item ranges from 1 to 5, high scores indicating high levels of support. The internal consistency coefficient obtained was .85 (Cronbach's $\alpha$ ).
Self-esteem. An 8-item scale was used (Warr \& Jackson, 1983). This scale was derived from a version of Rosenberg's Self-Esteem Scale (1965), adapted by Bachman and O'Malley (1977). The original scale attempted to assess processes related to adolescents' self-esteem. The adaptation permits the application of the scale to the general population. The items are statements of self-evaluation that are positive (e.g., I consider myself a useful person to have around) and negative (e.g., I haven't much to be proud of). The responses were graded from 1 to 7 in the case of positive selfevaluations, and from 7 to 1 in the case of negative selfevaluations. A high score (indicating a high level of selfesteem) can therefore be obtained either from a high level of agreement with the positive statements or a high level of disagreement with the negative statements. The internal consistency coefficient for the group in the present study was .77. The results of factorial analysis (principal components method, varimax rotation) yielded a single factor. In previous studies, the questionnaire showed a bifactorial structure (Warr \& Jackson, 1983). However, other studies have shown a one-dimensional structure of the original scale (Gray-Little, Williams, \& Hancock 1997; Pastor, Navarro, Tomás, \& Oliver, 1997). Furthermore, as pointed out by Carmines and Zeller (1979), the bifactorial solution may be the result of a statistical artifact. In our study, the structure was one-dimensional, and hence, the final score on the scale was the sum of the scores in each of the eight items.

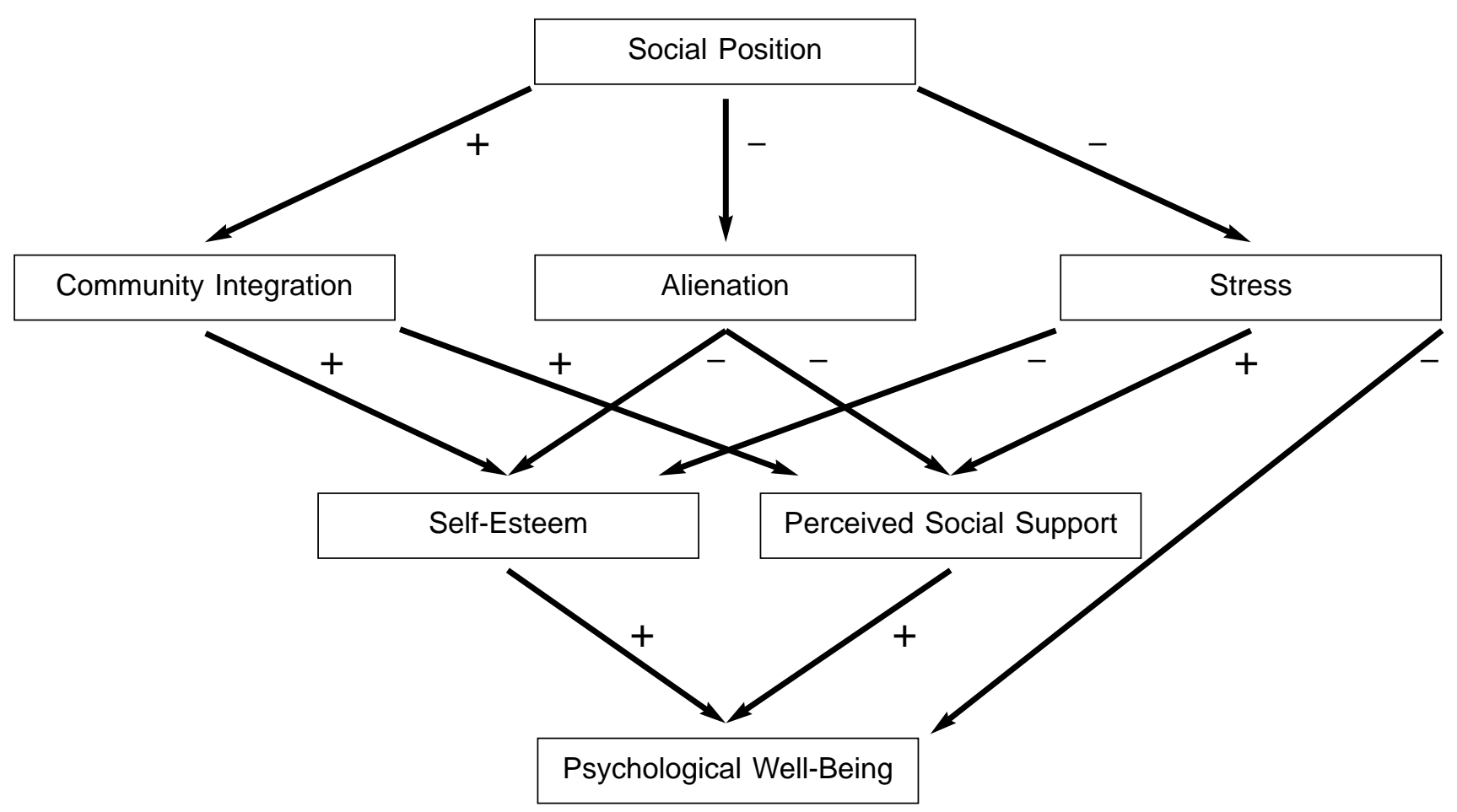

Figure 2. Hypothesized model. 
Results

Figure 2 shows the hypothesized recursive structural model. The error terms are not shown in the figure, although they were included in the estimation of the model. The measurement model is not shown in the figure, nor is it included in the analysis, because of the large number of variables it would require. However, all the instruments used in our research had adequate psychometric properties, as mentioned above. The maximum-likelihood method was employed to estimate the goodness of fit of the theoretical model with the sample data. We used the AMOS statistical program (Arbuckle, 1997) for the analysis.

The analysis of structural equations allows researchers to empirically evaluate theoretically-constructed models. In other words, the use of structural equations permits the rejection of models that are inconsistent with the data (Bollen, 1989). Given that the principal aim of the present study is to verify a theoretical model of psychological wellbeing, this data analysis technique is the most suitable for the empirical verification of our theoretical foundations.

The model hypothesized in Figure 2 did not fit the data, as indicated by various goodness-of-fit measures $\left(\chi^{2}=\right.$ 108.001, $p=.000$; Jöreskog and Sörbom's goodness-of-fit index, GFI $=.928 ;$ Jöreskog and Sörbom's adjusted goodness-of-fit index, AGFI $=.777 ; \delta^{2}=0.871 ; \rho^{2}=0.693$ ). Specifically, some of the hypothesized relationships were not statistically significant at conventional levels $(p<.05)$, whereas in the revised model (see Figure 3), other relationships appeared that had not been hypothesized. Thus, there was no relationship between community integration and self-esteem, nor did social support show a buffering effect. However, new, unexpected relationships came to light, such as the direct effect of community integration and alienation on psychological well-being, and the effect of community integration and stress on alienation. The results summarized in Figure 3 show that, as hypothesized, social position was inversely related to stress and alienation, and directly related to community integration. Similarly, stress had a negative impact on self-esteem and psychological well-being. Furthermore, a high level of alienation reduced individuals' perceived social support and self-esteem, whereas community integration increased the value of both variables. Lastly, our results confirmed that both self-esteem and perceived social support were directly related to psychological well-being, so that, as levels of support and self-esteem rose, psychological well-being increased.

\section{Discussion}

The principal goal of this study was to formulate and verify a socio-psychological model of mental health. Both the theoretical analysis and the results obtained in the

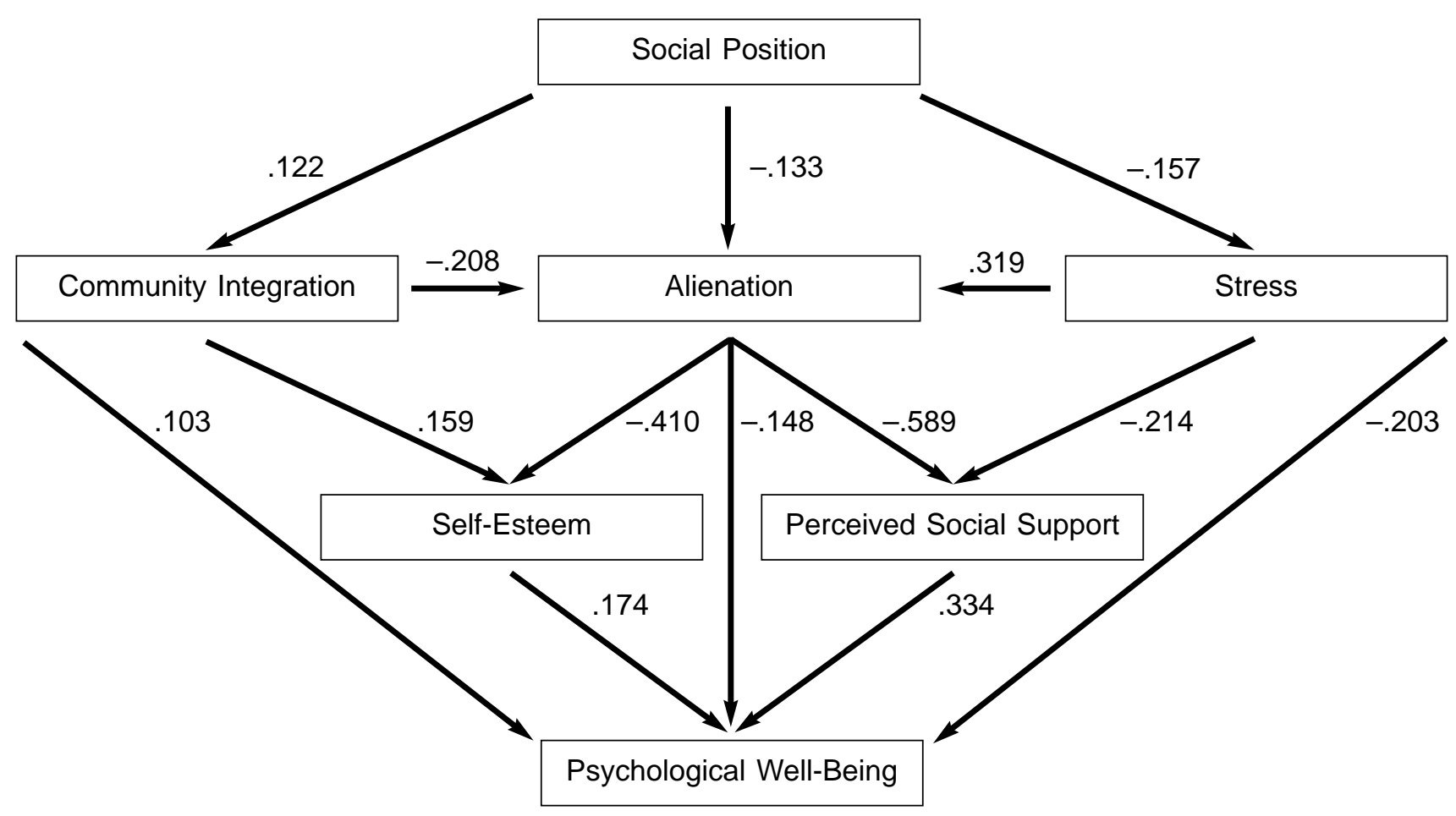

Figure 3. Structural equation model of psychological well-being. $\chi^{2}(5, N=401)=7.655, p=.176$; GFI $=0.995$; AGFI $=0.970$. All coefficients were statistically significant at $p<.05$. Although included in the statistical analysis, the error terms are not shown, in order to facilitate interpretation. The following error terms correlated: social position and psychological well-being; self-esteem and perceived social support. 
empirical study indicate the relevance of an approach that considers both socio-structural aspects and individual factors. In fact, the main aim was not to show the existence of an association between social structure and mental health, since this association appears systematically in various studies, as pointed out previously. However, the interrelations between structural and psychological factors that lead to a reduction in levels of psychological well-being have not received sufficient attention in the literature on this subject.

Our results reveal the need to consider psychological and sociological theories in combination when building a psycho-social model to account for mental health. In this respect, authors such as Stoppard (1998) indicate that the inadequacy of individual factors to explain distress has been clearly shown in psychological research, which has attempted to conceal this problem by introducing certain supposedly social variables. Nonetheless, the notion of social influence within the scope of these models is quite limited: "The social environment has been conceptualized in two main ways, one denoted by the term 'stress' or 'stressful life events' and the other referred to as 'social support', presumed to be derived from social relationships and networks" (Stoppard 1998; see also Avison \& Gotlib, 1994). If both variables, stress and social support, are considered social influences, then they should be considered in combination with people's social position.

Our results show how the stress suffered by individuals is related to their position in the social structure, so that more disadvantaged positions are a source of stressful experiences. At the same time, these disadvantaged positions are, in turn, associated with reductions in perceived social support. However, to explain this relationship, the role of certain collective variables should be considered-in our case, two dimensions of social integration: alienation and integration within the community. Social integration does not merely consist in keeping in touch with others and participating in community organizations, but also implies a pattern of relating to the normative and symbolic environment (alienation). In this sense, our data support the hypothesis that social integration is an important factor for the understanding of psychological deterioration. A good deal of this importance is derived from its effect on the variables that make up the psychosocial level of the relationship between social structure and mental health, as well as its direct effect on psychological well-being. The effect of social integration on mental health does not imply that the relevance of psychological factors should be rejected: It is possible that the negative effects of alienation on individuals are transmitted via certain variables operating at this level-in our study, self-esteem.

The finding that social support has no buffering effect against stress is particularly striking, especially as the literature on this subject indicates that perceived support normally has a buffering effect (Cohen \& Wills, 1985). However, this finding should be treated with caution, as our data do not contradict this buffering effect. When social variables (in our case, alienation) are introduced, the relationship between stress and social support probably changes. More specifically, stress can affect perception of support, but via alienation. As can be seen in Figure 3, higher levels of stress lead to higher associated measures of alienation. At the same time, alienation has a negative association with perception of support. In fact, the dimensions of anomie and cultural estrangement seem especially relevant, as they can block access to sources of support.

In summary, the present study emphasizes the social origin of psychological deterioration. Social structure has consequences for individuals, and, in this sense, there seems to be an imbalance in the distribution of mental health. Our data underline the importance of social integration, as well as the role of stress as an environmental factor. Nevertheless, the relationship between social position and psychological well-being cannot be understood without incorporating various psychological and psychosocial variables into our models. Thus, social support and self-esteem stand out as two essential variables, and constitute what House (1981) called the psychological principle.

The need to incorporate social and psychological variables into our models of mental health is the principal theoretical conclusion of our study. For this reason, and given current psychological and sociological tendencies, House's theoretical proposition $(1977,1981)$ emerges as the most suitable for the psychological study of mental health. Using this proposition, it seems possible to overcome the deficiencies of a false separation between disciplines that, by the nature of both their subject matter and their professional practices, are intimately related.

\section{References}

Álvaro, J.L. (1992). Desempleo y bienestar psicológico. Madrid: Siglo XXI.

Arbuckle, J.L. (1997). Amos users' guide (Version 3.6). Chicago: Smallwaters Corporation

Avison, R., \& Gotlib, I.H. (1994). Introduction and overview. In W.R. Avison \& I.H. Gotlib (Eds.), Stress and mental health. Contemporary issues and prospects for the future (pp. 3-12). New York: Plenum Press.

Bachman, J.G., \& O’Malley, P.M. (1977). Self-esteem in young men: A longitudinal analysis of the impact of educational and occupational attainment. Journal of Personality and Social Psychology, 35, 356-380.

Banks, M.H. (1983). Validation of the General Health Questionnaire in a young community sample. Psychological Medicine, 3, 349-353.

Barrón, A. (1993). La psicología comunitaria: una disciplina en busca de paradigma. Apuntes de Psicología, 32, 33-36.

Bollen, K.A. (1989). Structural equations with latent variables. New York: Wiley. 
Brage, D. \& Meredith, W. (1994). A causal model of adolescent depression. Journal of Psychology, 128, 455-468.

Brown, G.W., \& Harris, T. (1978). Social origins of depression. A study of psychiatric disorder in women. London: Tavistock.

Carmines, E.G., \& Zeller, R.A. (1979). Reliability and validity assessment. Beverly Hills, CA: Sage.

Cochrane, R., \& Sobol, M.P. (1980). Life stresses and psychological consequences. In P. Feldman \& J. Orford (Eds.), The social psychology of psychological problems (pp. 151-182). Chichester, UK: Wiley.

Cohen, S., \& Wills, T.A. (1985). Stress, social support and the buffering hypothesis. Psychological Bulletin, 98, 310-357.

Cutrona, C.E. (1986). Behavioral manifestations of social support: A microanalytic investigation. Journal of Personality and Social Psychology, 51, 201-208.

Durkheim, E. (1976). El suicidio. Madrid: Akal. (Original work published 1897).

Giddens, A. (1973). The class structure of advanced societies. London: Hutchinson.

Goldberg, D.P. (1978). Manual for the General Health Questionnaire. Windsor: National Foundation for Educational Research.

Gore, S., \& Aseltine, R.H. (1995). Protective processes in adolescence: Matching stressors with social resources. American Journal of Community Psychology, 23, 301-327.

Gray-Little, B., Williams, V.S.L., \& Hancock, T.D. (1997). An item response theory analysis for the Rosenberg Self-Esteem Scale. Personality and Social Psychology Bulletin, 23, 443-451.

Hepworth, S.J. (1980). Moderating factors of the psychological impact of unemployment. Journal of Occupational Psychology, 53, 139-145.

Herrero, J., Gracia, E., \& Musitu, G. (1996). Salud y comunidad. Evaluación de los recursos y estresores. Valencia, Spain: CSV.

House, J.S. (1977). The three faces of social psychology. Sociometry, 40, 161-177.

House, J.S. (1981). Social structure and personality. In M. Rosenberg \& R.H. Turner (Eds.), Social psychology. Sociological perspectives (pp. 525-561). New York: Basic Books.

House, J., \& Mortimer, J. (1990). Social structure and the individual: Emerging themes and new directions. Social Psychology Quarterly, 53, 71-80.

Kohn, M.L. (1976). Occupational structure and alienation. American Journal of Sociology, 82, 111-130.

Kunovich, R. M., \& Hodson, R. (1999). Civil war, social integration and mental health in Croatia. Journal of Health and Social Behavior, 40, 323-343.

Lin, N., Ye, X., \& Ensel, W.M. (1999). Social support and depressed mood: A structural analysis. Journal of Health and Social Behavior, 40, 344-359.

Marx, K. (1985). Manuscritos: Economía y filosofía. Madrid: Alianza. (Original work published 1844.)

Mirowsky, J., \& Ross, C.E. (1989). Social causes of psychological distress. New York: Aldine de Gruyter.

Mortimer, J.T., \& Lorence, J. (1979). Occupational experience and the self concept: A longitudinal study. Social Psychology Quarterly, 42, 307-323.
Parkin, F. (1979). Marxism and class theory: A bourgeois critique. London: Tavistock.

Pastor, A., Navarro, E., Tomás, J.M., \& Oliver, A. (1997). Efectos de método en escalas de personalidad: La escala de autoestima de Rosenberg. Psicológica, 18, 269-283.

Pearlin, L.I. (1989). The sociological study of stress. Journal of Health and Social Behavior, 30, 241-256.

Poulantzas, N. (1977). Classes in contemporary capitalism. London: NLB.

Roberts, B.R. (1987). A confirmatory factor-analytic model of alienation. Social Psychology Quarterly, 50, 346-351.

Roberts, J.E., \& Gotlib, I.H. (1997). Temporal variability in global self-esteem and specific self-evaluation as prospective predictors of emotional distress: Specificity in predictors and outcome. Journal of Abnormal Psychology, 106, 521-529.

Rosenberg, M. (1965). Society and the adolescent self-image. Princeton, NJ: University Press.

Sánchez, E. (1998). Apoyo social, integración social y salud mental. Revista de Psicología Social, 13, 537-544.

Seeman, M. (1959). On the meaning of alienation. American Sociological Review, 24, 783-791.

Seeman, M. (1983). Alienation motifs in contemporary theorizing: The hidden continuity of the classic themes. Social Psychology Quarterly, 46, 171-184.

Stafford, E. M. (1982). The impact of the youth opportunities programme on young people's employment prospects and psychological well-being. British Journal of Guidance and Counselling, 10, 12-21.

Stoppard, J.M. (1998). Dis-ordering depression in women. Theory and Psychology, 8, 79-99.

Thoits, P.A. (1982). Life stress, social support, and psychological vulnerability: Epidemiological considerations. Journal of Community Psychology, 10, 341-362.

Turner, R.J., \& Lloyd, D.A. (1999). The stress process and the social distribution of depression. Journal of Health and Social Behavior, 40, 374-404.

Van Parijs, P. (1993). Una revolución en la teoría de clases. In J. Carabaña \& A. de Francisco (Eds.), Teorías contemporáneas de las clases sociales (pp. 187-225). Madrid: Pablo Iglesias.

Warr, P., \& Jackson, P. (1983). Self-esteem and unemployment among young workers. Le Travail Humain, 46, 355-366.

Wethington, E., \& Kessler, R.C. (1986). Perceived support, received support, and adjustment to stressful life events. Journal of Health and Social Behavior, 27, 78-89.

Williams, D.R. (1990). Socioeconomic differentials in health: A review and redirection. Social Psychology Quarterly, 53, 8199.

Wright, E. O. (1989). Classes. London: Verso.

Wicker, A.W. (1989). Substantive theorizing. American Journal of Community Psychology, 17, 531-547.

Received October 22, 2002 Revision received February 17, 2003 Accepted March 18, 2003 